\title{
Vesicular (liposomal and nanoparticulated) delivery of curcumin: a comparative study on carbon tetrachloride-mediated oxidative hepatocellular damage in rat model
}

\author{
This article was published in the following Dove Press journal: \\ International Journal of Nanomedicine \\ 18 May 2016 \\ Number of times this article has been viewed
}

\author{
Somsubhra Thakur \\ Choudhury' \\ Nirmalendu Das ${ }^{2}$ \\ Swarupa Ghosh ${ }^{2}$ \\ Debasree Ghosh ${ }^{2}$ \\ Somsuta Chakraborty ${ }^{2}$ \\ Nahid Ali' \\ 'Infectious Diseases and Immunology, \\ ${ }^{2}$ Drug Development, Diagnostics and \\ Biotechnology, CSIR-Indian Institute \\ of Chemical Biology, Kolkata, West \\ Bengal, India
}

\begin{abstract}
The liver plays a vital role in biotransforming and extricating xenobiotics and is thus prone to their toxicities. Short-term administration of carbon tetrachloride $\left(\mathrm{CCl}_{4}\right)$ causes hepatic inflammation by enhancing cellular reactive oxygen species (ROS) level, promoting mitochondrial dysfunction, and inducing cellular apoptosis. Curcumin is well accepted for its antioxidative and anti-inflammatory properties and can be considered as an effective therapeutic agent against hepatotoxicity. However, its therapeutic efficacy is compromised due to its insolubility in water. Vesicular delivery of curcumin can address this limitation and thereby enhance its effectiveness. In this study, it was observed that both liposomal and nanoparticulated formulations of curcumin could increase its efficacy significantly against hepatotoxicity by preventing cellular oxidative stress. However, the best protection could be obtained through the polymeric nanoparticle-mediated delivery of curcumin. Mitochondria have a pivotal role in ROS homeostasis and cell survivability. Along with the maintenance of cellular ROS levels, nanoparticulated curcumin also significantly $(P<0.0001)$ increased cellular antioxidant enzymes, averted excessive mitochondrial destruction, and prevented total liver damage in $\mathrm{CCl}_{4}$-treated rats. The therapy not only prevented cells from oxidative damage but also arrested the intrinsic apoptotic pathway. In addition, it also decreased the fatty changes in hepatocytes, centrizonal necrosis, and portal inflammation evident from the histopathological analysis. To conclude, curcumin-loaded polymeric nanoparticles are more effective in comparison to liposomal curcumin in preventing $\mathrm{CCl}_{4}$-induced oxidative stress-mediated hepatocellular damage and thereby can be considered as an effective therapeutic strategy.
\end{abstract}

Keywords: reactive oxygen species, mitochondria, apoptosis, antioxidants, histopathology, Western blot

\section{Introduction}

Hepatotoxicity, harmful liver damage, is generally induced by different toxic chemicals like alcohol, carbon tetrachloride $\left(\mathrm{CCl}_{4}\right)$, aspirin, arsenic, diethylnitrosamine, etc. The liver plays a pivotal role in biotransforming and clearing these chemicals, and thus becomes susceptible to their toxicities. There are four stages of liver damage inflammation, fibrosis, cirrhosis, and hepatocellular carcinoma. Short-term administration of $\mathrm{CCl}_{4}$ causes hepatic injury, centrilobular necrosis, steatosis, and inflammation. ${ }^{1}$ Since human liver metabolizes $\mathrm{CCl}_{4}$ like that of rodents, $\mathrm{CCl}_{4}$-induced liver injury in rats can be an appropriate model for chemical-induced liver injury. The biotransformation of $\mathrm{CCl}_{4}$ takes place in liver, mainly catalyzed by different isotypes of cytochrome
Correspondence: Nahid Ali Infectious Diseases and Immunology Division, CSIR-Indian Institute of Chemical Biology, 4, Raja S.C. Mullick Road, Jadavpur, Kolkata 700032, West Bengal, India

Tel +9l 3324995757

Fax +9| $3324730284 / 5$ | 97

Email nali@iicb.res.in 
P450 such as CYP2E1, CYP2B1, CYP2B2, and CYP3A. In humans, CYP2E1 metabolizes at environmentally relevant concentrations, but, at higher concentrations, CYP3A makes a notable contribution in the breakdown of $\mathrm{CCl}_{4}$. Breakdown of $\mathrm{CCl}_{4}$ produces trichloromethyl $\left(\mathrm{CCl}_{3}{ }^{*}\right)$ and trichloromethyl peroxy $\left(\mathrm{CCl}_{3} \mathrm{OO} *\right)$ radicals. These highly reactive radicals preferentially bind with membrane phospholipids of different subcellular organelles like endoplasmic reticulum, mitochondria, and golgi apparatus of hepatocytes and cause lipid peroxidation and disruption of intracellular calcium homeostasis, resulting in the production of other reactive oxygen species (ROS). ${ }^{2,3}$ Mitochondria, the powerhouse of the cell, function as the principal source of ROS, which in turn damages mitochondria by forming lipohydroperoxide in mitochondrial membrane. This damage of the mitochondrial membrane causes opening of mitochondria permeability transition pores, disruption of mitochondrial membrane potential, and hindrance in normal electron transport chain and oxidative phosphorylation. These alterations in turn accelerate the oxidative stress in the hepatocytes. Furthermore, the extensive mitochondrial damage releases cytochrome c from mitochondrial membrane, which activates the caspase-mediated apoptotic death as well as cellular necrosis.

Curcumin (Cur) [diferuloylmethane] is a polyphenolic compound obtained from the rhizomes of Curcuma longa. Over the past few decades, extensive studies have been carried out to explore different pharmacological effects of this polyphenol, which demonstrates excellent antioxidant, antiinflammatory, and anticarcinogenic properties. ${ }^{4-7}$ Despite having multiple medicinal benefits, poor gastrointestinal (GI) absorption and lower oral bioavailability of this partially water-soluble compound restrict its use for effective therapy. ${ }^{8}$ Recent evidences show that heat-treated curcumin and its different water-soluble analogs can address the issue of stability and solubility in aqueous environment. ${ }^{9,10}$ However, the best bioavailability can be achieved through various drug delivery vehicles like nanoparticles, liposomes, micelles, etc, which have shown promising results by improving circulation time, increasing cellular permeability, and shielding the drug from metabolic degradation. ${ }^{11}$

Among the different drug delivery vehicles, liposomes and polymeric nanoparticles are considered the most beneficial for their high entrapment efficacy for both hydrophobic and hydrophilic substances and sustained and precise drug targeting. ${ }^{12}$ Recently, the polymeric nanoparticles have emerged as an attractive alternative to liposomes. The versatility of particulate technologies has enabled the use of polymeric nanoparticle-based drug delivery systems as they have many different advantages such as lower particle size, desired pharmacokinetic profile, improved bioavailability, and oral route of administration. Among the different drug delivery systems available in the market, biodegradable polymer poly(D,L-lactide-co-glycolide) (PLGA) is most commonly used because of its excellent biocompatibility. ${ }^{13}$

The aim of this study was to formulate curcumin-loaded liposomal and polymeric nanoparticulated formulations to overcome its solubility issue and improve the therapeutic efficacy of curcumin. Here we have shown that although liposomal curcumin can provide some protective efficacy against $\mathrm{CCl}_{4}$-mediated acute liver damage, better protection could be obtained through polymeric nanoparticulated delivery of curcumin. It was also found that nanoparticulated formulation could prevent both lethal oxidative stress as well as extensive mitochondrial damage. Additionally, protection against apoptotic and necrotic cellular damage and hepatocyte cellular architectural disruption was best observed in the PLGA nanoparticle-treated rats.

\section{Materials and methods Materials}

Bovine serum albumin (BSA), cholesterol, curcumin, dicetyl phosphate (DCP), 2,6-dichloroindophenol (DCIP), didodecyldimethylammonium bromide (DMAB), phosphatidylethanolamine (PE), poly(D,L-lactide-co-glycolide) (PLGA) (Resomer RG 85:15H), phenazine methosulfate (PMS), and succinic acid were purchased from Sigma-Aldrich (St Louis, MO, USA). CM-H DCFDA was obtained from Thermo Fisher Scientific (Waltham, MA, USA). Ethyl acetate (AR grade) was procured from Rankem Fine Chemicals (New Delhi, India). Chloroform and methanol were purchased from E Merck (Darmstadt, Germany). All other reagents were of analytical grade.

\section{Animals}

Adult female Swiss albino rats (with body weight of $\sim 150 \mathrm{~g}$ ), used for this study, were kept at laboratory conditions $\left(26^{\circ} \mathrm{C}-28^{\circ} \mathrm{C}, 60 \%-80 \%\right.$ relative humidity, and 12 hours light/dark cycle) for 7 days prior to the start of treatment and provided with adequate food and drinking water. The study was approved by and carried out under the guidelines of the Animal Ethics Committee, India (registration number 147/99/ CPC SEA, India). The experiments were performed according to the guidelines of "Principles of Laboratory Animal Care" (NIH publication number 85-23, 1985). 


\section{Preparation of curcumin-loaded liposomes}

Liposomes were prepared according to Gregoriadis and Ryman's method ${ }^{14}$ by solvent evaporation method. In brief, PE, cholesterol, DCP, and curcumin (molar ratio 7:1:1:1) were dissolved in chloroform and methanol mixture $(2: 1, \mathrm{v} / \mathrm{v})$ in a round-bottom flask. A thin film was prepared by evaporating the organic solvent mixture, and the film was desiccated overnight for complete removal of the solvents. Next day, the film was suspended in phosphate-buffered saline (PBS, pH 7.2) and sonicated for 30 seconds in a probe-type sonicator. To separate the liposome from the unencapsulated curcumin, the suspension was ultracentrifuged for 1 hour at $105,000 \times g$ (Sorvall WX Ultra 90; Rotor T-890, Thermo Fisher Scientific). To ensure the complete removal of unentrapped drug, the pellet was washed thoroughly with PBS and finally resuspended in $2 \mathrm{~mL}$ PBS.

\section{Preparation of curcumin-loaded nanoparticles}

Curcumin-encapsulated nanoparticles were prepared by a modified emulsion-diffusion evaporation method. ${ }^{15}$ In short, $71 \mathrm{mg}$ PLGA and $5 \mathrm{mg}$ curcumin were dissolved in 5 and $1 \mathrm{~mL}$ ethyl acetate, respectively. Then, both the solutions were mixed and added dropwise to an aqueous phase containing $1 \%$ DMAB. The oil-water emulsion was stirred for 3 hours at room temperature, followed by homogenization for 5 minutes at 15,000 rpm (high-speed homogenizer; Polytron PT4000; Polytron Kinematica, Lucerne, Switzerland). To remove the organic solvent completely, the homogenized solution was stirred in a water bath at $40^{\circ} \mathrm{C}$ for 2 hours. Nanoparticles were separated by ultracentrifugation (Sorvall WX Ultra 90; Rotor T-890, Thermo Fisher Scientific) at $105,000 \times g$ for 1 hour. To completely remove the unentrapped curcumin from the nanoparticulated formulation, the pellet was washed twice with PBS and finally resuspended in $2 \mathrm{~mL}$ of PBS. ${ }^{16}$

\section{Characterization of curcumin-loaded liposomes and nanoparticles}

Entrapment efficiency and in vitro release kinetics study

The entrapment efficiency of both the formulations was measured by spectrophotometry (Rayleigh, UV-2601 spectrophotometer; Beijing Beifen-Ruili Analytical Instrument (Group) Co., Ltd., Beijing, People's Republic of China). The pellet of the liposomal solution obtained through ultracentrifugation was dissolved in $2 \mathrm{~mL}$ methanol overnight at $4^{\circ} \mathrm{C}$. The same procedure was also followed for nanoparticles, where ethyl acetate was used instead of methanol. Finally, the amount of curcumin was measured at $450 \mathrm{~nm}$ by using a standard curve. The percentage of drug entrapped was calculated by the following formula:

Total amount of curcumin

$$
\begin{gathered}
\text { Entrapment } \\
\text { efficiency (\%) }
\end{gathered}=\frac{\text { in the pellet }}{\text { Initial amount of curcumin taken }} \times 100
$$

In vitro drug release study of curcumin from liposomes and nanoparticles was performed by direct dispersion method at $37^{\circ} \mathrm{C}$ and $\mathrm{pH} 7.4 .^{17,18} \mathrm{In}$ brief, a known quantity of both curcumin-loaded liposomes and nanoparticles were taken in $45 \mathrm{~mL}$ of $10 \mathrm{mM}$ PBS and each was divided into 45 microcentrifuge tubes (15 sets, each having three tubes). Then the tubes were kept at $37^{\circ} \mathrm{C} \pm 0.5^{\circ} \mathrm{C}$ under constant stirring at $50 \mathrm{rpm}$. At different time intervals, one set of tubes were taken out, centrifuged at $105,000 \times g$ for 1 hour. Both the released and entrapped curcumin were measured at $450 \mathrm{~nm}$, and a time versus cumulative drug release curve was plotted to understand the release kinetics of curcumin.

\section{Morphological features of curcumin-loaded liposomes and nanoparticles}

The size and morphological features of curcumin-loaded liposomal and nanoparticulated formulations were analyzed using an atomic force microscopic system (Pico plus 5500 AFM; Agilent Technologies, Santa Clara, CA, USA). In brief, samples were deposited onto a mica sheet, dried for 30 minutes, and then scanned by microfabricated silicon cantilevers. Images were processed using Pico view 1.10.1 software (Agilent Technologies). The histogram indicated the height of the sample from the mica sheet. ${ }^{19}$

\section{Pharmacokinetics study of free curcumin, curcumin- loaded liposomes, and nanoparticles}

Eighteen female Swiss albino rats were divided in three groups, with each group containing six animals. Two groups of rats received free curcumin $(8.98 \mu \mathrm{mol}$ curcumin dissolved in $0.5 \mathrm{~mL}$ aqueous suspension containing $0.2 \%$ dimethyl sulfoxide (DMSO) or $22 \mathrm{mg} / \mathrm{kg}$ body weight) and nanoparticulated curcumin $(0.5 \mathrm{~mL}$ suspension contains $8.98 \mu \mathrm{mol}$ curcumin or $22 \mathrm{mg} / \mathrm{kg}$ body weight) orally. The rats in the third group were administered liposomal curcumin intravenously through tail vein at the same dose $(0.5 \mathrm{~mL}$ suspension contains $8.98 \mu \mathrm{mol}$ curcumin or $22 \mathrm{mg} / \mathrm{kg}$ body weight). They were fasted overnight before dosing. Animals had access to food and water only after 4 hours of drug administration. 
Blood was collected into heparinized tubes by retro-orbital puncture at 15 and 30 minutes and 1, 2, 4, 10, 20, 25, and 30 hours after administration of curcumin. Plasma was isolated from blood by centrifugation and stored at $-20^{\circ} \mathrm{C}$ prior to high performance liquid chromatography (HPLC) analysis. ${ }^{20}$

HPLC was performed using an $\mathrm{XBridge}^{\mathrm{TM}} \mathrm{C}_{18}$ column $(4.6 \times 250 \mathrm{~mm}, 5 \mu \mathrm{m}$ particle size, Waters, Milford, MA, USA) with a mobile phase composed of acetonotrile- $5 \%$ acetic acid $(75: 25 \mathrm{v} / \mathrm{v})$ at a flow rate of $1.0 \mathrm{~mL} / \mathrm{min}$. The wavelength for detection was $450 \mathrm{~nm}$, injection volume was $50 \mu \mathrm{L}$, and analysis time was $10 \mathrm{~min} /$ sample.

The calculations were done using the Kinetic software (Kinetica 5.0, Thermo Fisher Scientific). The area under the curve (AUC) was calculated using the trapezoidal method.

\section{Stability of the curcumin-loaded liposomes and nanoparticles}

Stability of curcumin-loaded liposomes and nanoparticles were studied according to change in their encapsulation efficiency at two different temperatures, $37^{\circ} \mathrm{C}$ and $4^{\circ} \mathrm{C}$. In short, known amounts of each the formulation were taken in $36 \mathrm{~mL}$ of $10 \mathrm{mM}$ PBS. They were divided into 36 microcentrifuge tubes (two sets each with 18 tubes). These two sets were incubated at two different temperatures $\left(37^{\circ} \mathrm{C}\right.$ and $\left.4^{\circ} \mathrm{C}\right)$. At predetermined time points $(0,1,2,7,14$, and 21 days $)$, three tubes were taken out from both the temperatures for both the formulations and encapsulation efficacies were calculated as already described. Then, time versus encapsulation efficacy was plotted to determine the stability of the formulations. ${ }^{21}$

\section{Induction of hepatotoxicity}

Hepatotoxicity was induced in all the rats (except the normal control group) through a single subcutaneous (SC) injection of $\mathrm{CCl}_{4}(40 \% \mathrm{v} / \mathrm{v}$ in olive oil, $1 \mathrm{~mL} / \mathrm{kg}$ body weight). Normal control animals were injected with a single dose of olive oil ( $1 \mathrm{~mL} / \mathrm{kg}$ body weight). Free curcumin $(8.98 \mu \mathrm{mol}$ curcumin dissolved in $0.5 \mathrm{~mL}$ aqueous suspension containing $0.2 \%$ DMSO), empty and curcumin-loaded nanoparticles $(0.5 \mathrm{~mL}$ suspension contains $8.98 \mu \mathrm{mol}$ curcumin) were administered orally, while empty and curcumin-loaded liposomes $(0.5 \mathrm{~mL}$ suspension contains $8.98 \mu \mathrm{mol}$ curcumin) were injected into the tail vein 2 hours prior to $\mathrm{CCl}_{4}$ administration.

After 24 hours of $\mathrm{CCl}_{4}$ administration, animals were sacrificed, and blood and liver were collected. ${ }^{22}$ Serum was isolated from the blood, and different liver toxicity marker enzymes (serum aspartate transaminase [AST], alkaline phosphatise [AP], and serum alanine transaminase [ALT]) were measured using SGOT(ASAT) Kit (Reitman \& Frankel's method); Alkaline Phosphatase Kit (Mod. Kind and King's method); SGPT(ALAT) Kit (Reitman and Frankel's method) (Coral Clinical Systems, Goa, India). ${ }^{19}$ The liver was divided into two parts: one was fixed in $10 \%$ formalin solution for histopathological analysis, while the other part was utilized for preparation of mitochondrial and cytosolic extract. ${ }^{23}$

\section{Preparation of mitochondria and submitochondrial particles}

Conventional differential centrifugation method was chosen for isolation of liver mitochondria and submitochondrial particles according to the method of Navarro and Boveris. ${ }^{24}$ All the biochemical studies were performed within 5 hours of mitochondrial isolation.

\section{Preparation of cytosolic fraction}

The cytosolic fraction from the liver was prepared by homogenizing the organ in $0.25 \mathrm{M}$ sucrose solution, followed by two-step centrifugation at $8,200 \times g$ and $105,000 \times g$, respectively. ${ }^{25}$

\section{Biochemical analysis and enzymatic studies}

Mitochondrial ROS level

ROS level in mitochondrial fraction was analyzed spectroflurimetrically (LS 3B, PerkinElmer, Waltham, MA, USA) using a cell permeable probe, $\mathrm{CM}-\mathrm{H}_{2}$ DCFDA [5-(and-6)-chloromethyl$2^{\prime}, 7^{\prime}$-dichlorodihydro-fluorescein diacetate acetyl ester]. ${ }^{26}$ The values obtained in experimental groups were compared with the normal group, considering normal as $100 \%$.

\section{Mitochondrial lipid peroxidation}

The conjugated diene/lipohydroperoxide formed in the membrane reflects lipid peroxidation level. First, the mitochondrial membrane was extracted with chloroform-methanol $(2: 1, v / v)$ mixture, and then the lipohydroperoxide level was evaluated according to the method of Mandal et al. ${ }^{27}$

\section{Mitochondrial membrane fluidity}

Mitochondrial membrane fluidity was studied spectroflurimetrically by measuring the intensity of the fluorescence probe diphenyl hexatriene (DPH) both in parallel $\left(I_{\mathrm{II}}\right)$ and perpendicular $\left(I_{\perp}\right)$ directions of the polarization of the excited light. Microviscosity $(r)$ was calculated using the equation, $r=\left(I_{\mathrm{II}}-I_{\perp}\right) /\left(I_{\mathrm{II}}+2 I_{\perp}\right) \cdot{ }^{28}$

Succinate dehydrogenase (SDH) and nicotinamide adenine dinucleotide (NADH) oxidase activity

$\mathrm{SDH}$ and NADH oxidase activities were evaluated from liver submitochondrial particles. In brief, PMS-mediated 
reduction of DCIP at different time points was measured to estimate SDH activity according to Reddy and Weber's method. ${ }^{29} \mathrm{NADH}$ oxidase activity depends on the oxidation of $\mathrm{NADH}$ at $340 \mathrm{~nm} .^{30}$

\section{Reduced glutathione (GSH) and other cellular antioxidants status estimation}

Reduced glutathione level in cytosolic fraction was determined spectrophotometrically following the method of Davila et al. ${ }^{31}$ Superoxide dismutase (SOD) (EC 1.15.1.1) was assessed by detecting pyrogallol autoxidation according to Marklund and Marklund's method. ${ }^{32}$ Catalase activity was determined by $\mathrm{H}_{2} \mathrm{O}_{2}$ consumption rate, and enzyme activity was expressed as the amount of $\mathrm{H}_{2} \mathrm{O}_{2}$ reduced $/ \mathrm{min} / \mathrm{mg}$ of protein. ${ }^{33}$ By measuring the rate of NADH oxidation spectrophotometrically at $340 \mathrm{~nm}$, glutathione reductase (GR) was assayed. ${ }^{34}$ Glutathione-S-transferase (GST) and glutathione-6-phosphate dehydrogenase (G6PDH) activities were measured according to the methods of Maiti and Chatterjee $^{35}$ and Ghosh et al, ${ }^{25}$ respectively.

\section{Western blot analysis of i-NOS, caspase 3, caspase 9 ,} and PARP

For immunoblotting analysis, the cytosolic fraction containing protease and phosphatidase inhibitor was first prepared, followed by sodium dodecyl sulfate-polyacrylamide gel electrophoresis (SDS-PAGE). The proteins were transferred (15 V, 20 minutes) to a polyvinylidene fluoride membrane using semidry transfer apparatus (Transblot, Bio-Rad Laboratories Inc., Hercules, CA, USA). After blocking with 4\% BSA overnight, the membranes were incubated with primary inducible nitric oxide synthase (i-NOS), caspase 3, caspase 9, and PARP antibodies. Alkaline phosphatase-conjugated secondary antibody was used. Bands were visualized by using Sigma premixed 5-bromo-4-chloro-3-indolyl-phoshate/nitroblue tetrazolium substrate solution.

\section{Statistical analysis}

All the results were expressed as mean \pm standard deviation (SD) for five replicates. The significance of differences between mean values was calculated by Student's $t$-test using GraphPad Prism 5 (GraphPad Software, Inc., La Jolla, CA, USA), and it was considered significant only when $P<0.05$.

\section{Results}

\section{Characterization of nanoparticles}

The physicochemical characteristics of a formulation determine the efficacy of the drug delivery vehicle. Investigation of the size and surface morphology of curcumin-loaded liposomes and nanoparticles by AFM revealed that the liposomes are much larger in size $(140 \pm 60 \mathrm{~nm})$ in comparison to the nanoparticulated formulation of curcumin $(35 \pm 9 \mathrm{~nm}$; Figure 1 and Table 1). Both the particles were spherical in shape. The morphology was intact, no cracks and pores were observed, and no significant aggregation was noticed. The nanoparticles showed narrower size distribution in comparison to liposomes. The topological analysis showed that the heights of liposomes were more $(4 \mathrm{~nm})$ than that of the nanoparticles $(2 \mathrm{~nm})$. The encapsulation of curcumin was higher in liposomes $(84 \% \pm 3 \%)$ in comparison to nanoparticles $(72 \% \pm 5 \%$; Table 1$)$.

Study of the in vitro drug release kinetics showed a burst in the release of approximately $37 \%$ of the drug in the first 20 hours in the case of nanoparticulated formulation, and after that a sustained release pattern was observed. The liposomal formulation, on the other hand, showed a steady release pattern till 48 hours (Figure 2).

Pharmacokinetics of free, liposomal, and nanoparticilated curcumin showed that free curcumin has very low bioavailability in the plasma. Because of the intravenous injection, liposomal curcumin showed a high $C_{\max }$ value $(3.3 \mu \mathrm{g} / \mathrm{mL})$ at an early time point (15 minutes), which decreased significantly with time $\left(K_{\mathrm{el}}: 0.34\right.$ hour $\left.^{-1}\right)$. In comparison, nanoparticulated curcumin has shown a much higher $\mathrm{AUC}_{(0-\infty)}$ value, with significantly lower $K_{\mathrm{el}}\left(0.11\right.$ hour $\left.^{-1}\right)$ and with almost four times more bioavailability in comparison to liposomal curcumin (Figure 3 and Table 2).

Stability studies have indicated that both the formulations degrade at $37^{\circ} \mathrm{C}$, whereas at $4^{\circ} \mathrm{C}$ both are stable (Figure 4).

\section{Effect of curcumin-loaded liposomes and nanoparticles in preventing hepatic toxicity}

As subcutaneous administration of $40 \% \mathrm{CCl}_{4}$ at $1 \mathrm{~mL} / \mathrm{kg}$ body weight causes steatosis and fatty deposition in liver, the levels of three hepatocellular marker enzymes AP, AST, and ALT in serum were evaluated in different groups of animals (Table 3). A significant increase in these serum enzyme levels was observed in $\mathrm{CCl}_{4}$-treated group of rats as compared to normal rats. Free curcumin mixture and empty delivery vehicles (both liposome and nanoparticles) exerted no significant protection against hepatotoxicity. A significant protection was observed in the case of liposomal curcumin-treated animals, but the lowest toxicity was observed in nanoparticulated curcumin-treated animals. 

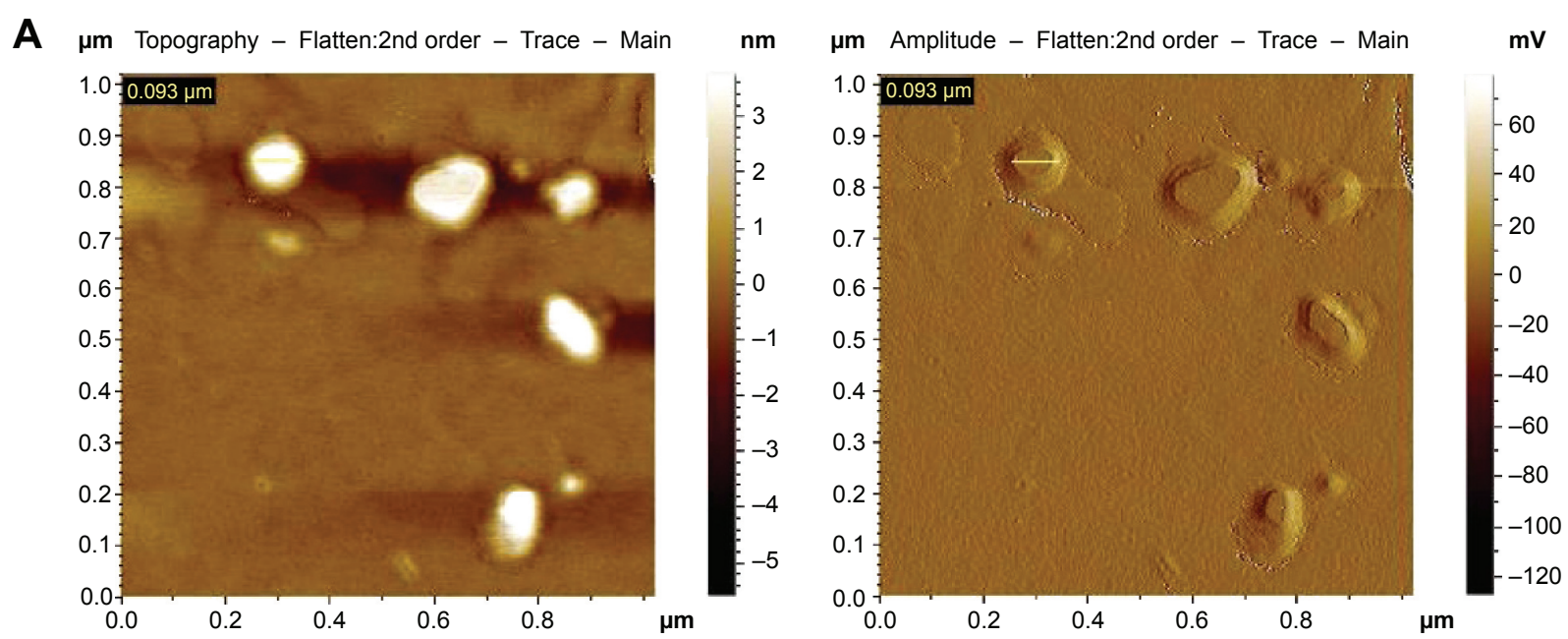

$\mathrm{nm}$

Topography vs distance

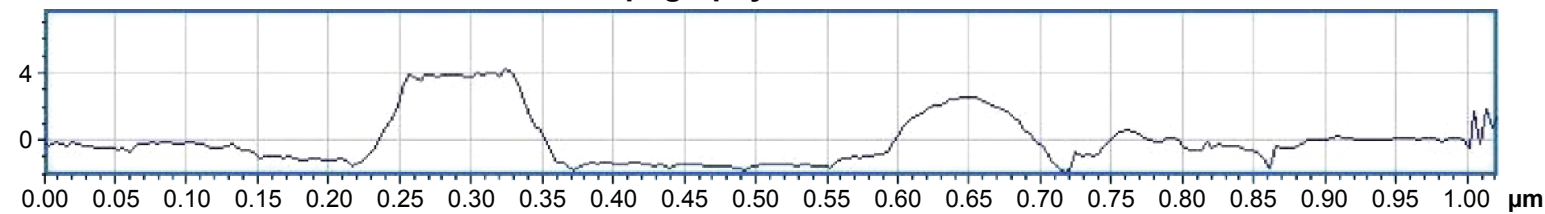

B $\quad \mu m$ Topography - Flatten:2nd order - Trace - Main
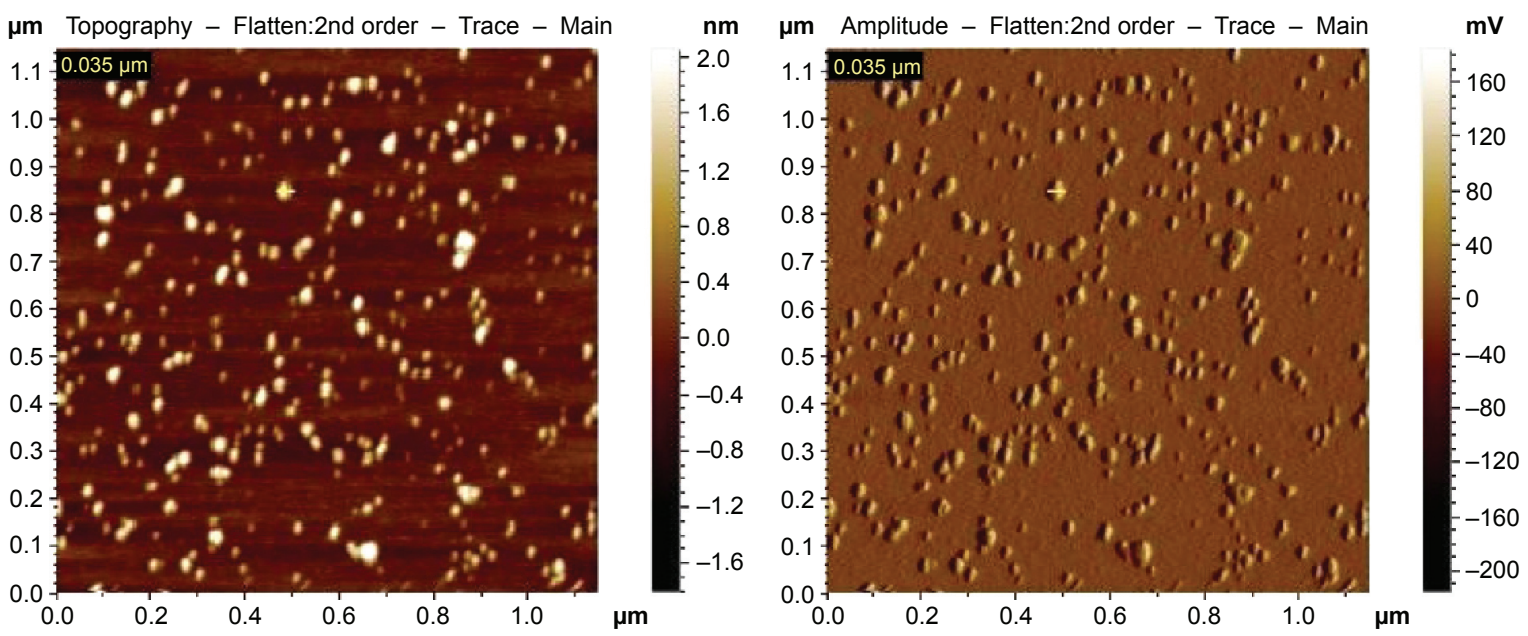

$\mathrm{nm}$

Topography vs distance

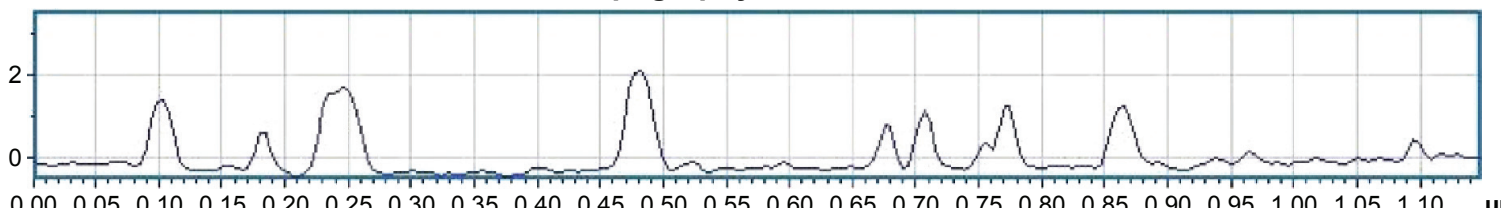

Figure I Atomic force microscopic images of (A) curumin-loaded liposomes and (B) PLGA-coated curcumin nanoparticles.

Note: Topography indicates the height of liposomes and nanoparticles from the substratum, mica sheet.

Abbreviation: PLGA, poly(D,L-lactide-co-glycolide).

\section{Effect of curcumin-loaded liposomes} and nanoparticles on the generation of mitochondrial ROS

$\mathrm{CCl}_{4}$ exerts its hepatotoxic effects by increasing the level of cellular ROS. The excess ROS generated in the cell further affects different subcellular organelles including mitochondria. Treatment of rats with $\mathrm{CCl}_{4}$ led to almost a threefold increase in mitochondrial ROS in comparison to the normal controls (Figure 5). Although free drug showed little or no protection, liposomal curcumin showed significant 
Table I Entrapment efficacy and mean particle size of curcuminloaded liposomes and nanoparticles

\begin{tabular}{lll}
\hline Sample name & \% encapsulation & $\begin{array}{l}\text { Mean particle } \\
\text { size (nm) }\end{array}$ \\
\hline $\begin{array}{l}\text { Curcumin-encapsulated } \\
\text { liposome }\end{array}$ & $84 \pm 3$ & $140 \pm 60$ \\
$\begin{array}{l}\text { Curcumin-encapsulated } \\
\text { nanoparticle }\end{array}$ & $72 \pm 5$ & $35 \pm 9^{*}$ \\
\hline
\end{tabular}

Notes: Results are expressed as mean \pm SD. Mean particle size of curcuminencapsulated nanoparticles was compared with liposomal curcumin and showed significant difference $(* P<0.01)$.

Abbreviation: SD, standard deviation.

protection against $\mathrm{CCl}_{4}$-induced ROS development. However, the most promising effect was observed in those rats that were treated with nanoparticulated curcumin.

\section{Effect of curcumin-loaded liposomes and nanoparticles against oxidative damage of mitochondria and submitochondrial particles}

Excess generation of ROS causes extensive mitochondrial damage by generating conjugated dienes as a result of lipid peroxidation and thereby reducing membrane microviscosity. The extent of mitochondrial damage was studied by measuring the mitochondrial diene formation (Figure 6), mitochondrial membrane microviscosity, and SDH and NADH oxidase activities (Table 4). $\mathrm{CCl}_{4}$ administration accelerated cellular diene formation in $\mathrm{CCl}_{4}$-treated control animals, thereby decreasing mitochondrial membrane potential. The free drug showed no significant effect in preventing ROS-mediated mitochondrial damage. Liposomal curcumin showed a significant protective effect by preventing mitochondrial diene formation and thereby preserving mitochondrial membrane integrity - as evident from mitochondrial membrane viscosity.

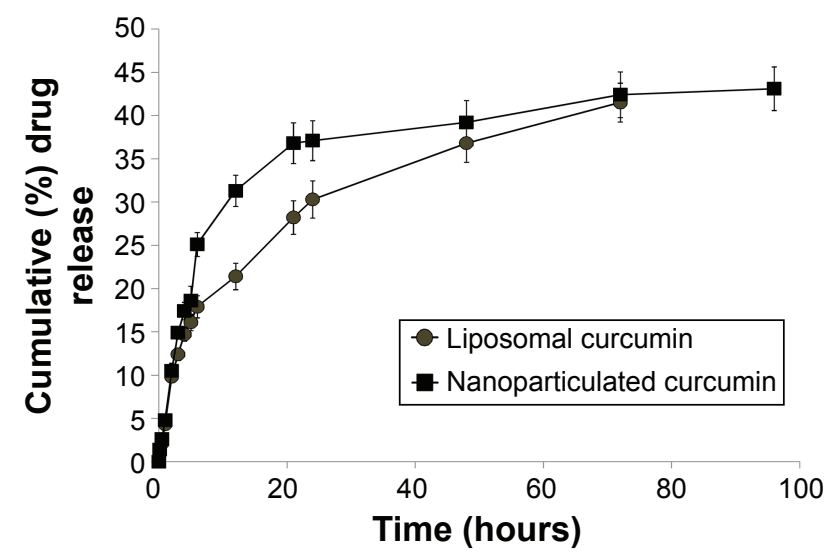

Figure 2 In vitro release kinetics profile of liposomal and nanoparticulated curcumin.

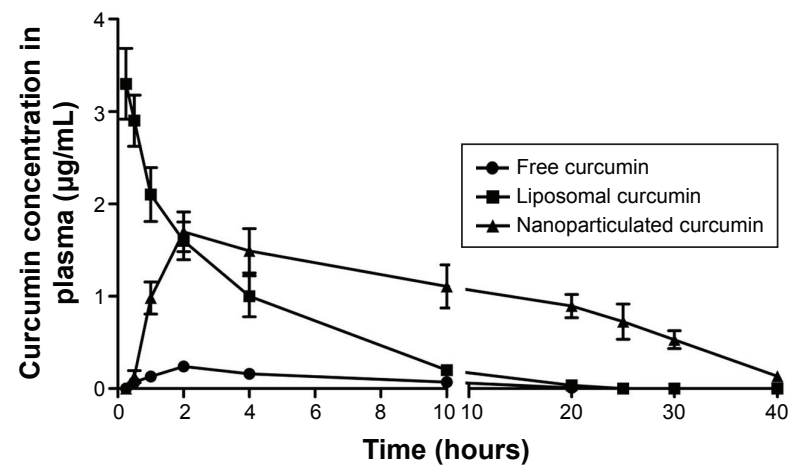

Figure 3 Plasma concentration of curcumin after treatment with free, liposomal, and nanoparticulated curcumin.

Studies on other mitochondrial marker enzymes like SDH and NADH oxidase also proved that liposomal curcumin could provide some protection (Table 4). However, the best mitochondrial protection could be obtained in rats treated with nanoparticulated curcumin.

\section{Effect of curcumin-loaded liposomes and nanoparticles on antioxidant status of the liver}

The body has endogenous antioxidants to combat against excess ROS intrinsically. But during oxidative stress, the depletion of these cellular antioxidants takes place. GSH, the most important intracellular antioxidant, showed a marked reduction in $\mathrm{CCl}_{4}$-treated control animals. Other cellular antioxidants like SOD, catalase, G6PDH, GR, and GST showed the same trend. Free and liposomal curcumin showed no significant protection in preventing the depletion of antioxidants. But very promising results were found in the rats treated with nanoparticulated curcumin (Table 5).

\section{Pathomorphology of liver section}

Pathomorphology of normal rats (Figure 7A) revealed that hepatocytes were arranged in cords around hepatic vein forming hepatic lobules. The portal tracts were also normal. The liver section of $\mathrm{CCl}_{4}$-injected rats showed marked hepatic damage, considerable fatty deposition in the cells along with partial periportal fibrosis (Figure 7B), massive portal inflammation, and centrizonal necrosis (Figure 7C). Similar tissue damage, including fibrosis and steatosis, was also evident in free curcumin-treated animals (Figure 7D and E). Treatment with liposomal curcumin led to commendable prevention of the damage, although some cells with fat deposition along with deformed cellular architecture were still observed in the histopathological analysis (Figure 7F). Liver sections from animals treated with nanoparticulated 
Table 2 Pharmacokinetics parameters of free curcumin and curcumin-loaded liposomes and nanoparticles

\begin{tabular}{|c|c|c|c|}
\hline \multirow[t]{2}{*}{ Route of administration } & Free curcumin & Liposomal curcumin & Nanoparticulated curcumin \\
\hline & Oral & Intravenous & Oral \\
\hline Dose (mg/kg b wt) & 22 & 22 & 22 \\
\hline$C_{\max }(\mu g / m L)$ & $0.24 \pm 0.03$ & $3.30 \pm 0.38$ & $1.69 \pm 0.22$ \\
\hline$T_{\max }(\mathrm{h})$ & 2 & 0.25 & 2 \\
\hline$K_{\mathrm{el}}\left(\mathrm{h}^{-1}\right)$ & 0.20 & 0.34 & 0.11 \\
\hline $\mathrm{AUC}_{0-\infty}(\mu \mathrm{g} / \mathrm{mL} / \mathrm{min})$ & 97.5 & 647.32 & $2,025.59$ \\
\hline$F_{\text {Rel }}$ (with respect to free curcumin) & - & 6.64 & 20.77 \\
\hline$F_{\text {Rel }}$ (with respect to liposomal curcumin) & - & - & 3.13 \\
\hline
\end{tabular}

Note: Data for $C_{\max }$ are represented as mean $\pm \mathrm{SD}(\mathrm{n}=6)$.

Abbreviations: $C_{\max }$, maximum concentration; $T_{\max }$, time at $C_{\max } ; K_{\mathrm{el}}$, elimination rate constant; AUC, area under the curve; $F_{\text {Rel' }}$, relative bioavailability; b wt, body weight.

curcumin demonstrated the most efficient prevention against $\mathrm{CCl}_{4}$ administration, with cellular morphology almost comparable to normal rats.

\section{Nitric oxide synthase 2 and intrinsic} caspase pathway markers immunoblotting Nitric oxide synthase 2, i-NOS, is one of the key markers of free-radical-mediated cellular damage. Administration of $\mathrm{CCl}_{4}$ increased the expression of i-NOS approximately sixfold (Figure 8). While free and liposomal curcumin could prevent this stress to a certain extent, nanoparticulated curcumin showed a significant reduction $(P<0.001)$ in i-NOSmediated cellular damage.

Mitochondrial damage triggered the intrinsic apoptotic pathway, which was evident from the upregulation of caspase 3 cleavage, elevated levels of cleaved caspase 9 , and poly(ADP-ribose) polymerase (PARP) in $\mathrm{CCl}_{4}$-administered animals (Figure 8). Although liposomal curcumin showed some effect in preventing this apoptosis-mediated damage, the best protection was observed in nanoparticulated curcumin-treated tissue samples, where 2.5-fold lesser

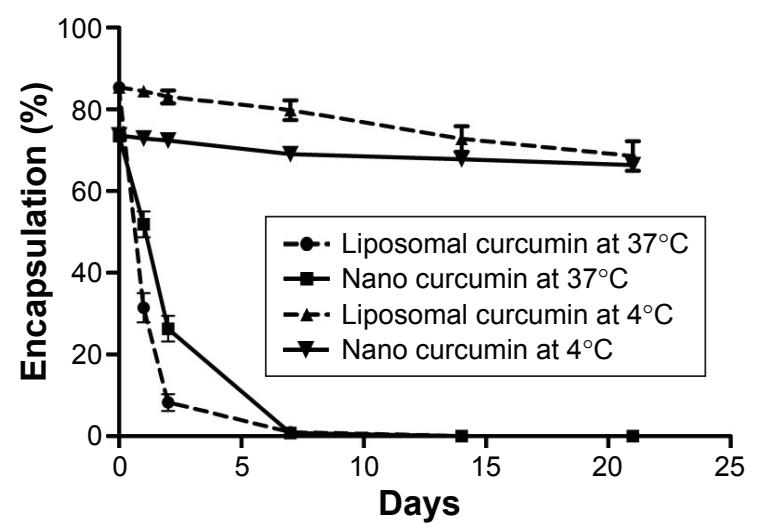

Figure 4 Stability study of curcumin-loaded liposomal and nanoparticulated formulations at $4^{\circ} \mathrm{C}$ and $37^{\circ} \mathrm{C}$. cleavage of caspase 3 took place. By preventing the cleavage of caspase 3, it also prevented further breakage of caspase 9 and PARP-1, which was reflected in the effect of nanoparticulated curcumin in preventing DNA damage and apoptosis.

\section{Discussion}

$\mathrm{CCl}_{4}$ is an effective hepatotoxic agent, and even a single exposure can promote severe liver toxicity, including necrosis and steatosis. Hence, $\mathrm{CCl}_{4}$ is widely used as a model for evaluating the hepatoprotective activity of new drugs or drug formulations. ${ }^{36,37}$ Our study suggested an enhancement of the efficacy of a traditional antioxidant, curcumin, when formulated with two delivery devices, liposome and nanoparticle. Both liposomal as well as nanoparticulated curcumin have shown better competence in scavenging cellular ROS, maintaining cellular antioxidant enzyme levels, preventing mitochondrial damage and intrinsic apoptotic pathway, and averting i-NOS overexpression. Further evidence suggested the nanoparticulated formulation of curcumin to be more effective than free and liposomal curcumin in preventing $\mathrm{CCl}_{4}$-mediated liver damage.

Oxidative stress is a principal aspect of hepatic damage. Our group has previously demonstrated that galactosegrafted liposome encapsulating an antioxidant can provide significant protection against $\mathrm{CCl}_{4}$-mediated fatty liver damage or steatosis. ${ }^{28}$ We have taken this study forward and compared the protective efficacy of curcumin-loaded polymeric nanoparticles with curcumin-loaded liposomes. Liposomes have several disadvantages for oral delivery as the lipid bilayer cannot withstand the harsh conditions in the GI tract. Since polymeric nanoparticles can be absorbed efficiently through the GI tract, the noninvasive oral delivery of polymeric nanoparticles is more advisable. Keeping our aim to deliver both the formulations through their best possible routes in this study, we delivered the curcumin-loaded 
Table 3 Effect of curcumin-loaded liposomes and nanoparticles on hepatic toxicity in $\mathrm{CCl}_{4}$-induced hepatic damage

\begin{tabular}{llll}
\hline Groups & Alkaline phosphatase (KA units) & Serum AST (IU/L) & Serum ALT (IU/L) \\
\hline Normal & $34.5 \pm 1.9$ & $112.5 \pm 6.3$ & $37.8 \pm 3.6$ \\
CCl $_{4}$ treated (A) & $89.8 \pm 2.3^{* *}$ & $247.1 \pm 7.9^{* *}$ & $116.7 \pm 3.5^{* *}$ \\
A + empty liposome treated & $79.8 \pm 4.3$ & $242.83 \pm 7.5$ & $111.5 \pm 4.3$ \\
A + empty nanocapsule treated & $78.2 \pm 3.6$ & $239.3 \pm 8.5$ & $109.2 \pm 2.0$ \\
A + free Cur treated & $67.9 \pm 2.0 I^{\#}$ & $205.8 \pm 5.8^{\#}$ & $87.5 \pm 4.6^{\#}$ \\
A + liposomal Cur treated & $59.9 \pm 2.2^{\# \#}$ & $176.1 \pm 7.9^{\#}$ & $59.5 \pm 7.2^{\#}$ \\
A + nanocapsulated Cur treated & $48.3 \pm 1.2^{\# \#}$ & $131.4 \pm 7.5^{\#}$ & $48.5 \pm 3.7^{\#}$ \\
\hline
\end{tabular}

Notes: Results of each group were expressed as mean $\pm \mathrm{SD}$ of five animals. $\mathrm{CCl}_{4}$-treated controls were compared with normal animals $(* * \mathrm{P}<0.00 \mathrm{I})$ and other experimental groups showed significant difference ( ${ }^{\# P} P 0.00 \mathrm{I}$ and $\# P<0.01$ ) from the $\mathrm{CCl}_{4}$-treated control group (A).

Abbreviations: AST, aspartate transaminase; ALT, alanine transaminase; SD, standard deviation.

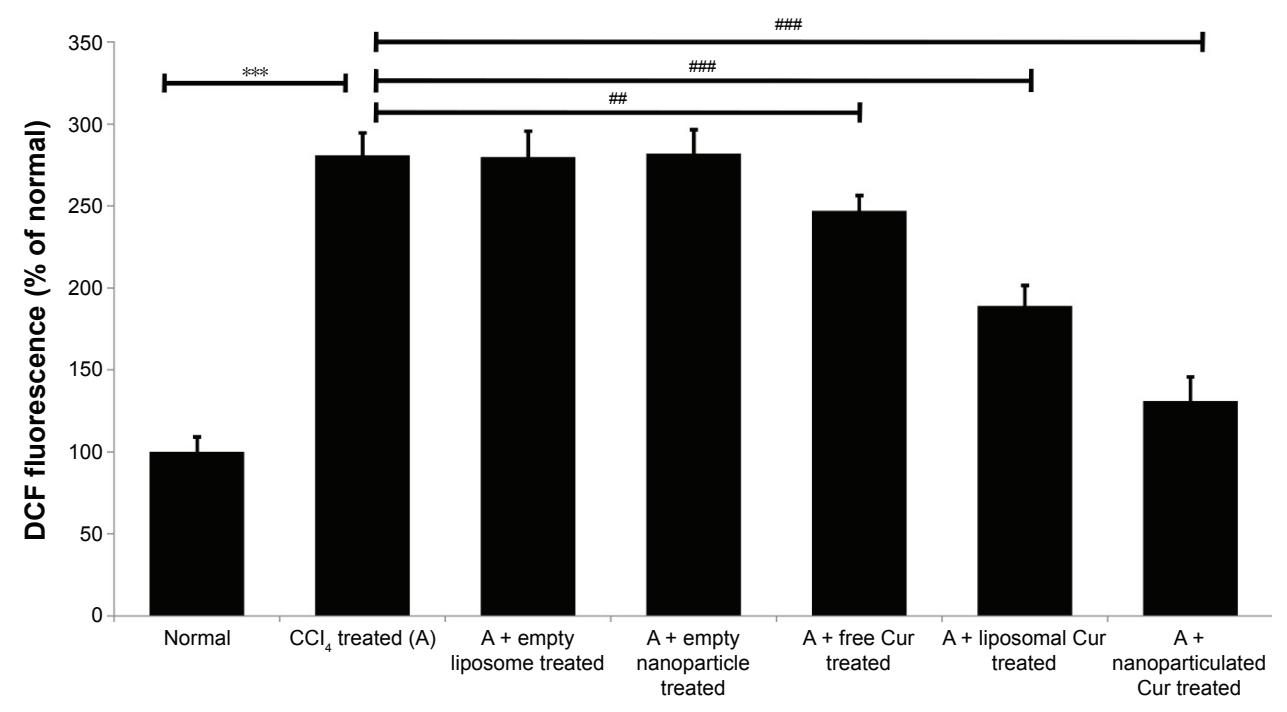

Figure 5 Values of ROS in liver mitochondria of rats.

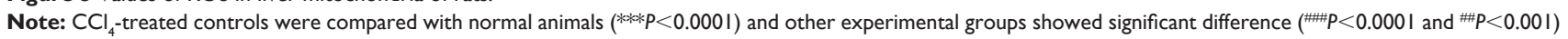
from the $\mathrm{CCl}_{4}$-treated control group (A).

Abbreviation: ROS, reactive oxygen species.

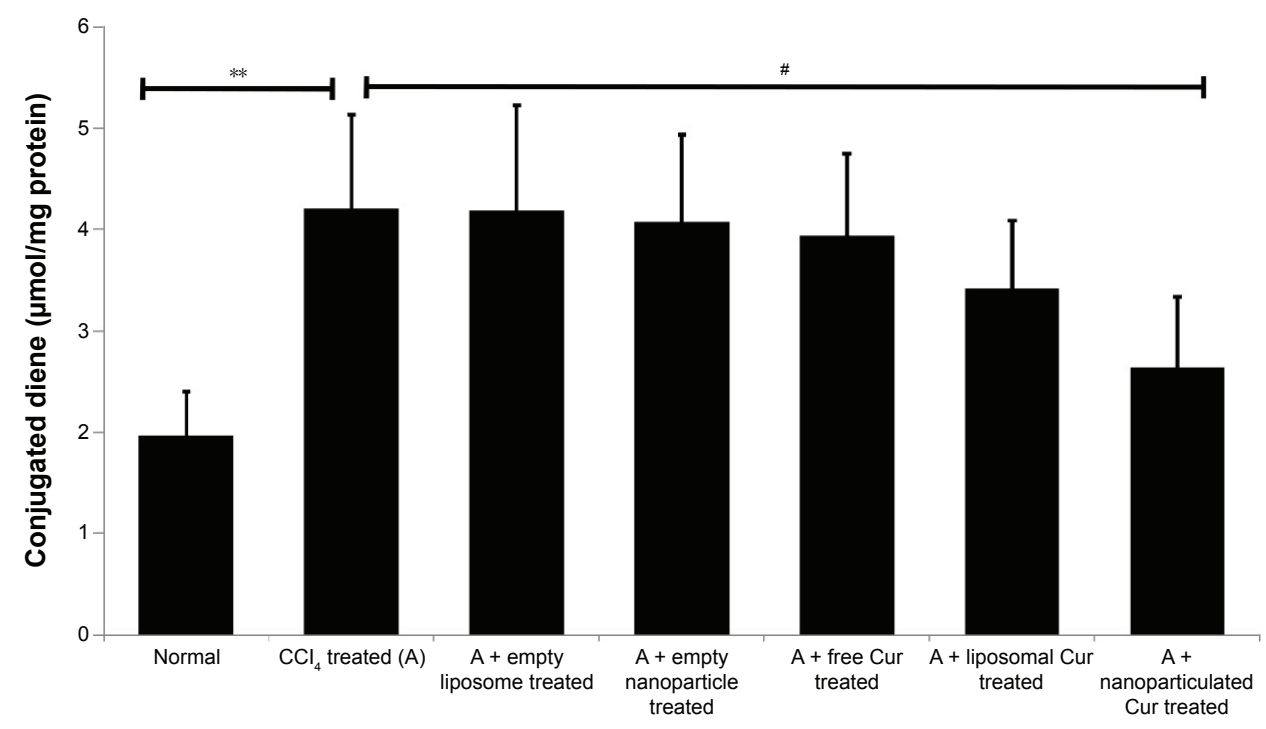

Figure 6 Effect of liposomal and nanoparticulated Cur on lipohydroperoxide level in rats liver mitochondria.

Note: $\mathrm{CCl}_{4}$-treated controls were compared with normal animals $(* * P<0.00 \mathrm{I})$ and other experimental groups showed significant difference $\left({ }^{\sharp} P<0.0 \mathrm{I}\right)$ from the $\mathrm{CCl}$-treated control group $(A)$. 
Table 4 Effect of curcumin-loaded liposomes and nanoparticles on ROS, NADH oxidase, and SDH levels in rat liver mitochondria

\begin{tabular}{|c|c|c|c|}
\hline Groups & $\begin{array}{l}\text { Membrane microviscosity } \\
\left(\left[r^{\circ} / r-I\right]-I\right)\end{array}$ & $\begin{array}{l}\text { NADH oxidase level (nmol } \\
\text { of oxidized NADH/min/mg pr) }\end{array}$ & $\begin{array}{l}\text { SDH activity ( } \mu \text { L DCIP } \\
\text { reduced } / \mathrm{min} / \mathrm{mg} \mathrm{pr} \text { ) }\end{array}$ \\
\hline Normal & $0.645 \pm 0.05 I$ & $5.74 \pm 0.19$ & $0.69 \pm 0.02$ \\
\hline $\mathrm{CCl}_{4}$ treated $(\mathrm{A})$ & $0.337 \pm 0.059 * * *$ & $7.17 \pm 0.76 * *$ & $0.24 \pm 0.02 * * *$ \\
\hline A + empty liposome treated & $0.329 \pm 0.067$ & $7.09 \pm 0.69$ & $0.24 \pm 0.02$ \\
\hline A + empty nanocapsule treated & $0.347 \pm 0.021$ & $7.09 \pm 0.31$ & $0.33 \pm 0.05$ \\
\hline$A+$ free Cur treated & $0.422 \pm 0.076$ & $6.89 \pm 0.52$ & $0.30 \pm 0.02$ \\
\hline A + liposomal Cur treated & $0.497 \pm 0.065^{\#}$ & $6.74 \pm 0.19$ & $0.45 \pm 0.06^{\# \#}$ \\
\hline$A+$ nanocapsule Cur treated & $0.605 \pm 0.037^{\# \# \#}$ & $5.92 \pm 0.32^{\#}$ & $0.62 \pm 0.05^{\ldots \#}$ \\
\hline
\end{tabular}

Notes: Results of each group were expressed as mean $\pm \mathrm{SD}$ of five animals. $\mathrm{CCl}_{4}$-treated controls were compared with normal animals $(* * * P<0.000 \mathrm{I}, * * P<0.00 \mathrm{I})$ and other experimental groups showed significant difference $\left({ }^{\# P}<0.000 \mathrm{I}\right.$ and ${ }^{\#} \mathrm{P}<0.00 \mathrm{I}$ ) from the $\mathrm{CCl}_{4}$-treated control group (A).

Abbreviations: ROS, reactive oxygen species; NADH, nicotinamide adenine dinucleotide; SDH, succinate dehydrogenase; DCIP, 2,6-dichloroindophenol; SD, standard deviation; pr, protein.

liposomes intravenously and nanoparticulated formulation orally.

Curcumin has various biological activities. It has been reported to have antioxidative, anticarcinogenic, anti-inflammatory, and immunomodulatory properties, with insignificant toxicity. ${ }^{38-40} \mathrm{~A}$ number of medicinal properties of curcumin have already been reviewed extensively in recent years. ${ }^{41,42}$ But as curcumin is insoluble in water, it has very poor GI absorption and thereby low bioavailability. Recent studies have shown that drug delivery devices such as nanoparticles and liposomes offer a potential opportunity to overcome the challenges associated with insoluble drugs like curcumin ${ }^{43}$ Studies herein have demonstrated that both the delivery devices (liposome and nanoparticle) are spherical in shape with small particle size and higher encapsulation efficiency (Figure 1 and Table 1). The comparatively smaller particle size of nanoparticles $(35 \mathrm{~nm})$ over liposomes $(140 \mathrm{~nm})$ helps in better cellular uptake of the nanoparticulated formulation. Moreover, pharmacokinetics studies show that nanoparticulated curcumin remains in the system for a much longer time than the liposome-loaded curcumin ( $\mathrm{AUC}_{0-\infty}$ is higher and $K_{\mathrm{el}}$ is lower). Relative bioavailability of nanoparticulated formulation is almost four times higher than liposomal formulation (Figure 3 and Table 2). Also, the initial burst release of the nanoparticulated curcumin as compared to a steady release from liposome (Figure 2) may provide an added advantage to the nanoparticulated formulation to combat the $\mathrm{CCl}_{4}$-mediated cellular damage.

$\mathrm{CCl}_{4}$ exerts its hepatotoxic effect through extensive ROS production. $\mathrm{CCl}_{4}$ is biotransformed by hepatic microsomal cytochrome $\mathrm{P} 450$ to produce toxic metabolites, trichloromethyl $\left(\mathrm{CCl}_{3}{ }^{*}\right)$ and trichloromethyl peroxy $\left(\mathrm{CCl}_{3} \mathrm{OO} *\right)$ radicals, which further trigger oxidative stress, cellular inflammation, and massive cellular damage. The mitochondrion is the bioenergetic and metabolic center of eukaryotic cells. ${ }^{36,44}$ The mitochondrion is the target as well as the source of ROS and peroxynitrite. $\mathrm{CCl}_{3}{ }^{*}$ and $\mathrm{CCl}_{3} \mathrm{OO}$ * exhibit a strong affinity for membrane lipids of the cell and different subcellular organelles and generate lipohydroperoxide. The extensive formation of ROS and reactive nitrogen species within the mitochondria triggers the opening of mitochondrial membrane permeability transition pores, decrease of mitochondrial membrane fluidity, and collapse of mitochondrial membrane potential. This extensive mitochondrial damage is the critical step in liver injury. ${ }^{45,46}$ Mitochondrial outer membrane permeabilization leads to the release of mitochondrial intermembrane protein cytochrome $\mathrm{c}$ into the cytosol. In the cytosol, cytochrome c binds to Apaf-1 and activates caspase 9, which triggers caspase 3-mediated apoptotic pathway. ${ }^{3}$ Our studies have shown that the mitochondrial lipohydroperoxide levels that increased significantly due to $\mathrm{CCl}_{4}$ administration were arrested by liposomal and nanoparticulated curcumin treatment. However, the best prevention was seen in nanoparticulated curcumin-treated animals (Figure 6). Prevention of mitochondrial damage was also evident from the levels of mitochondrial membrane microviscosity, ie, the fluidity of the membrane and mitochondrial marker enzymes, NADH oxidase, and SDH activity (Table 4). Because of the protection of the mitochondria and their membranes, the cytochrome c-mediated intrinsic apoptotic pathway was successfully arrested by treatment with nanoparticulated curcumin (Figure 8).

Mitochondrial damage by $\mathrm{CCl}_{4}$ further triggers excessive production of other cellular ROS like superoxide $\left(\mathrm{O}_{2}^{\circ}\right)$, hydrogen peroxide $\left(\mathrm{H}_{2} \mathrm{O}_{2}\right)$, and hydroxyl radicals $\left({ }^{\circ} \mathrm{OH}\right)$ and causes cellular necrosis. ${ }^{47}$ Continuous interaction of these free radicals with different cellular components like protein, lipid, DNA, carbohydrates, and membrane generates various cellular adducts that cumulatively cause cellular damage. The prime function of antioxidative defense 


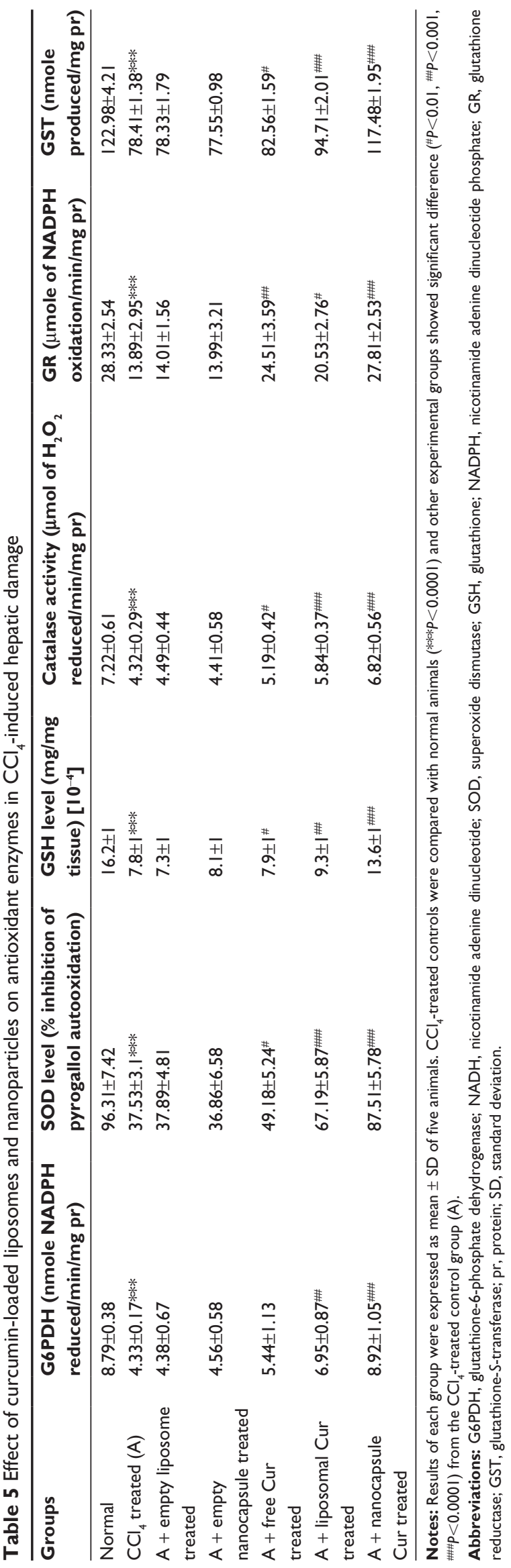

systems is suppression of generation of ROS, scavenging of ROS, clearance by neutralization, repairing and reconstitution of damage, and induction of antioxidant proteins and enzymes ${ }^{48}$ Reduced glutathione (GSH) plays a critical role of coenzyme and participates in the removal of free radicals and peroxides, maintains membrane thiols, and also acts as a substrate for different antioxidant marker enzymes like glutathione peroxidase (GPx), GR, and GST. ${ }^{49} \mathrm{SOD}, \mathrm{CAT}$, and GPx mutually constitute a supportive enzyme system of the first line of cellular defense against reactive oxidants by decomposing $\mathrm{O}_{2}^{\cdot}$ and $\mathrm{H}_{2} \mathrm{O}_{2}$ to prevent the formation of more harmful hydroxyl and alkoxyl radicals. ${ }^{50}$ The decrease of all these antioxidant enzyme levels (Table 5) was due to extensive oxidative stress and higher ROS level (Figure 5) in the cellular system. Both liposomal and nanoparticulated curcumin have shown promising results against this oxidative stress by preventing the increase in ROS and maintaining cellular antioxidants balance.

Nitric oxide (NO) plays a crucial role as a vasodilator, neurotransmitter, and an antimicrobial agent in the normal body system. ${ }^{51}$ However, the role of NO in hepatic damage remains controversial. Although some studies have shown that $\mathrm{NO}$ protects against $\mathrm{CCl}_{4}$-induced liver injury, a good number of studies have also shown excessive NO production by i-NOS causing extensive hepatocellular damage. ${ }^{52-55}$ The latter hypothesis supported our results in which i-NOS expression increased significantly in liver homogenate of $\mathrm{CCl}_{4}$-intoxicated group, which could be prevented by the administration of nanoparticulated curcumin (Figure 8).

Portal inflammation and centrizonal necrosis are other most common effect of liver damage by $\mathrm{CCl}_{4}$. Hepatocytes comprise almost $70 \%-80 \%$ of the liver mass and include different cells like endothelial cells, stellate(Ito) cells, and mainly, Kupffer cells. Kupffer cells are the hot spot of hepatic inflammation as they are mainly involved in antigen presentation and clearance of particulates from portal circulation. Initial tissue damage and focal tissue necrosis release proinflammatory cytokine, tumor necrosis factor- $\alpha$, and interleukin-1, which may induce apoptosis or initiate inflammatory processes, leading to extensive liver damage. ${ }^{56}$ Histopathological studies have shown that $\mathrm{CCl}_{4}$ administration extensively damages the liver cellular architecture, leading to centrizonal necrosis, portal fibrosis, and marked steatosis. This damage was prevented by liposomal and nanoparticulated curcumin administration. However, the best protection was observed with curcumin nanoparticles (Figure 7). The downregulation of liver toxicity marker enzymes (namely, 

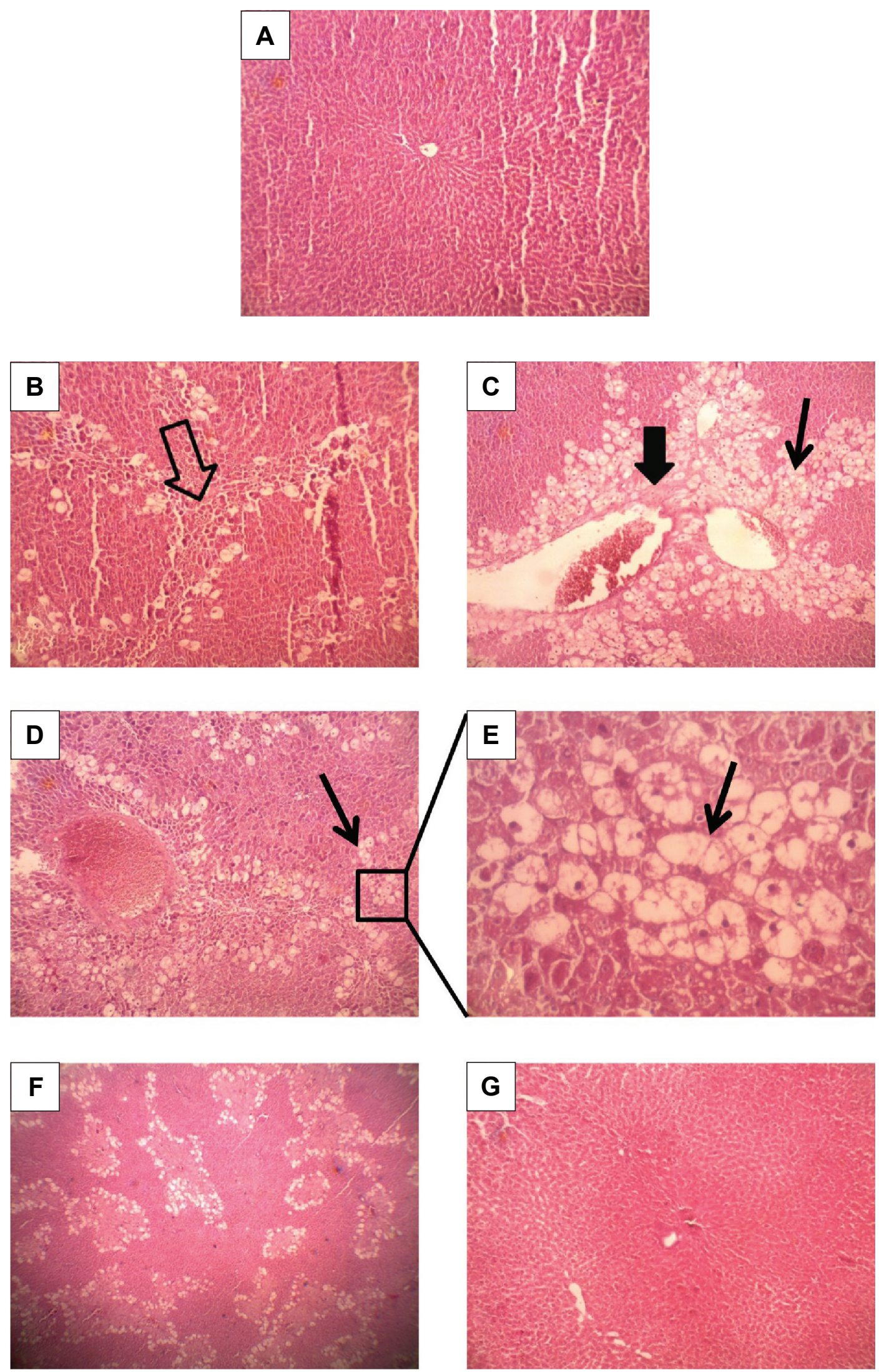

Figure 7 Hematoxylin-Eosin-stained liver section of normal and experimental rats.

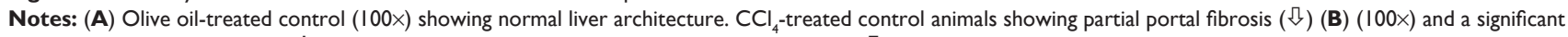
number of fat-deposited cells $(\downarrow)$ along with portal inflammation and centrizonal necrosis ( $)$ (C) (I00x). (D) $\mathrm{CCl}_{4}+$ free Cur-treated animals (I00x) showing some deformed cellular architecture with a large number of fatty acid-deposited cells, which is much clear with a higher magnification (400x) (E). CCl $4+$ lipo Cur treated (F) (100x) also showing some fat-deposited cells. (G) $\mathrm{CCl}_{4}+$ nano Cur treated (100x), showing architecture similar to normal. 

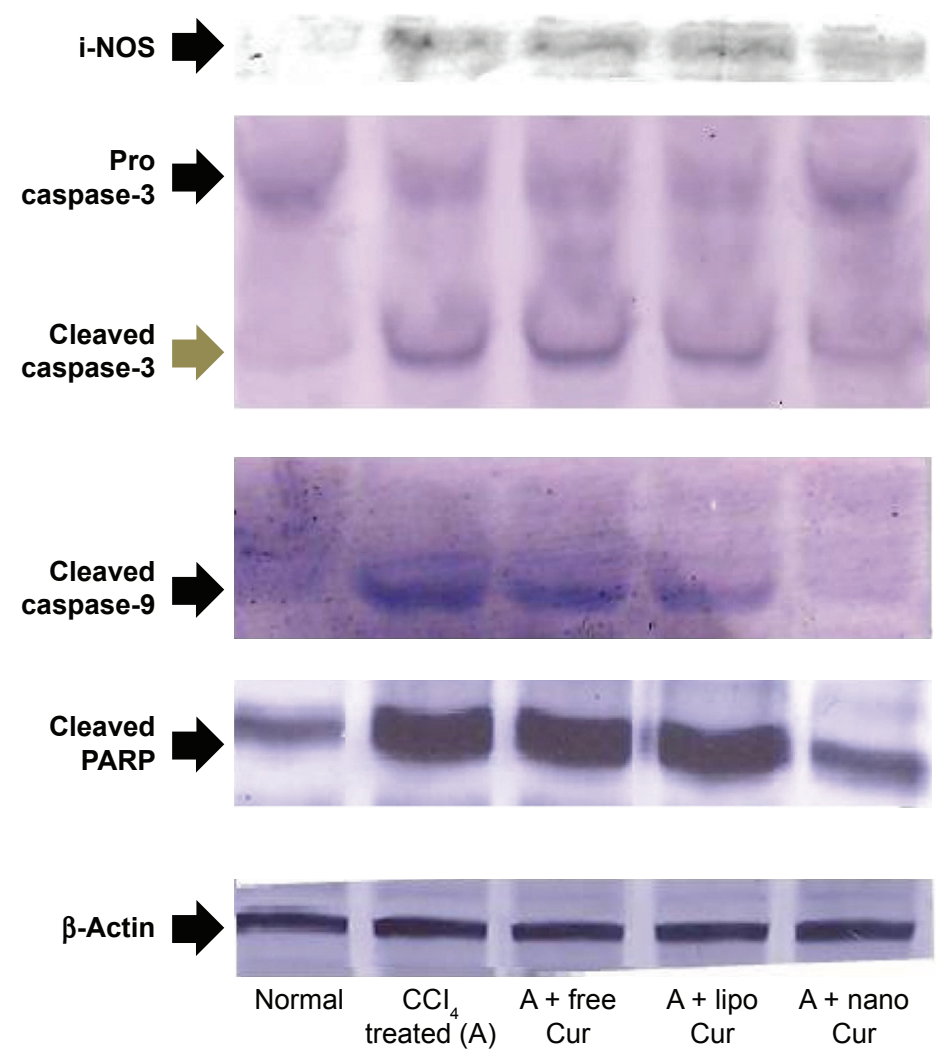
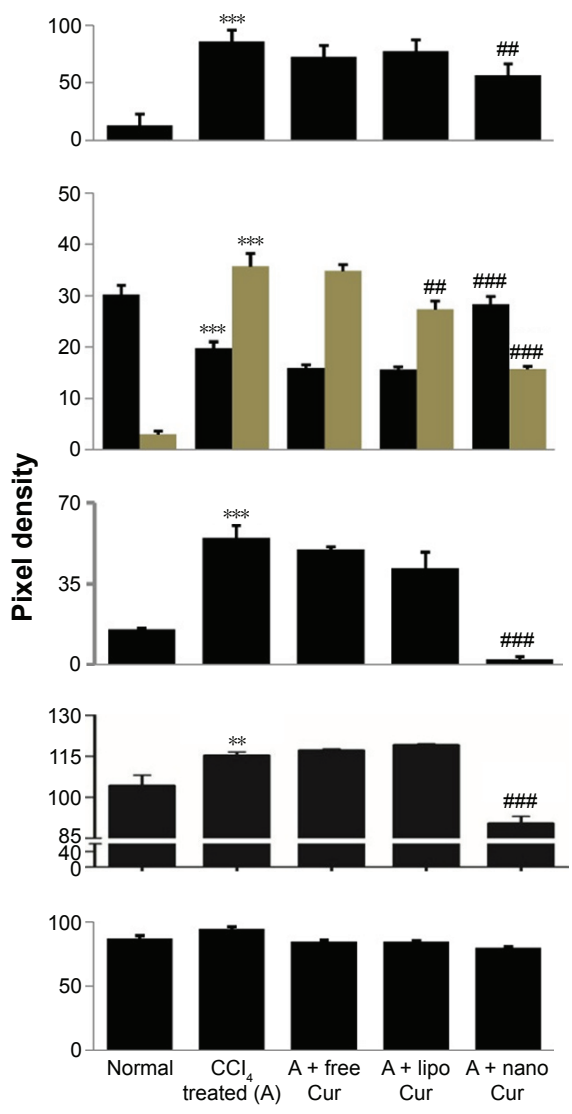

Figure 8 Western blot showing expression of inflammatory modulator (i-NOS) and different intrinsic apoptotic pathway markers.

Notes: Fold changes of expression (measured by ImageJ software) have been shown along with the blot. Control group (CCl treated) was compared with normal, and the value was significantly different where $* * P<0.001$, $* * * P<0.0001$, ${ }^{\# P}<0.001$, and ${ }^{\# \#} P<0.0001$ are significantly different from the $C C l_{4}$-treated control group $(A)$.

Abbreviation: i-NOS, inducible nitric oxide synthase.

AP, AST, and ALT) proved that a genuine protection can be provided by this nanoparticulated formulation (Table 3 ).

\section{Conclusion}

The results obtained strongly demonstrate the efficacy of nanoparticulated curcumin in preventing $\mathrm{CCl}_{4}$-mediated fatty liver damage or steatosis. Curcumin possesses excellent antioxidative and anti-inflammatory properties; however, because of low oral bioavailability, curcumin is not an effective drug against liver damage. Both liposomal as well as nanoparticulated formulations can increase the efficacy of curcumin many fold. However because of its small size, better cellular absorption, and longer persistence in the circulating system, curcumin-loaded nanoparticles can be considered as a promising therapeutic strategy against liver toxicity.

\section{Acknowledgments}

This work was funded by the Council of Scientific and Industrial Research (CSIR), Government of India. The authors recognize Dr Anjan Kumar Das, Associate Professor, Department of Pathology, Calcutta National Medical College and Hospital, Kolkata, India, for the interpretation of histopathological images; and T Muruganandan, Technical Officer, IICB Kolkata, India, for his support during the AFM study. The authors also acknowledge Prof Siddhartha Roy, ex-Director IICB, for his overall scientific guidance.

\section{Disclosure}

The authors report no conflicts of interest in this work.

\section{References}

1. Pierce RA, Glaug MR, Greco RS, Mackenzie JW, Boyd CD, Deak SB Increased procollagen mRNA levels in carbon tetrachloride-induced liver fibrosis in rats. $J$ Biol Chem.1987;262(4):1652-1658.

2. Recknagel RO. Carbon tetrachloride hepatotoxicity. Pharmacol Rev. 1967;19(2):145-208.

3. Bajt ML, Cover C, Lemasters JJ, Jaeschke H. Nuclear translocation of endonuclease $\mathrm{G}$ and apoptosis-inducing factor during acetaminopheninduced liver cell injury. Toxicol Sci. 2006;94(1):217-225.

4. Ruby AJ, Kuttan G, Babu KD, Rajasekharan KN, Kuttan R. Anti-tumour and antioxidant activity of natural curcuminoids. Cancer Lett. 1995; 94(1):79-83.

5. Lantz RC, Chen GJ, Solyom AM, Jolad SD, Timmermann BN. The effect of turmeric extracts on inflammatory mediator production. Phytomedicine. 2005;12(6-7):445-452. 
6. Aggarwal BB, Kumar A, Bharti AC. Anticancer potential of curcumin: preclinical and clinical studies. Anticancer Res. 2003;23(1A): 363-398.

7. Shi M, Cai Q, Yao L, Mao Y, Ming Y, Ouyang G. Antiproliferation and apoptosis induced by curcumin in human ovarian cancer cells. Cell Biol Int. 2006;30(3):221-226.

8. Lopez-Lazaro M. Anticancer and carcinogenic properties of curcumin: considerations for its clinical development as a cancer chemopreventive and chemotherapeutic agent. Mol Nutr Food Res. 2008; 52(Suppl 1):S103-S127.

9. Kurien BT, Singh A, Matsumoto H, Scofield RH. Improving the solubility and pharmacological efficacy of curcumin by heat treatment. Assay Drug Dev Technol. 2007;5(4):567-576.

10. Basile V, Ferrari E, Lazzari S, Belluti S, Pignedoli F, Imbriano C. Curcumin derivatives: molecular basis of their anti-cancer activity. Biochem Pharmacol. 2009;78(10):1305-1315.

11. Hani U, Shivakumar HG. Solubility enhancement and delivery systems of curcumin a herbal medicine: a review. Curr Drug Deliv. 2014;11(6): 792-804.

12. Allen TM, Cullis PR. Liposomal drug delivery systems: from concept to clinical applications. Adv Drug Deliv Rev. 2013;65(1):36-48.

13. Stevanovic M, Savic J, Jordovic B, Uskokovic D. Fabrication, in vitro degradation and the release behaviours of poly(DL-lactide-co-glycolide) nanospheres containing ascorbic acid. Colloids Surf B Biointerfaces. 2007;59(2):215-223.

14. Gregoriadis G, Ryman BE. Lysosomal localization of -fructofuranosidase-containing liposomes injected into rats. Biochem J. 1972; 129(1):123-133.

15. HariharanS, Bhardwaj V, BalaI, Sitterberg J,BakowskyU, RaviKumarMN. Design of estradiol loaded PLGA nanoparticulate formulations: a potential oral delivery system for hormone therapy. Pharm Res. 2006;23(1):184-195.

16. Lala S, Gupta S, Sahu NP, et al. Critical evaluation of the therapeutic potential of bassic acid incorporated in oil-in-water microemulsions and poly-D, L-lactide nanoparticles against experimental leishmaniasis. J Drug Target. 2006;14(4):171-179.

17. Bisht S, Feldmann G, Soni S, Ravi R, Karikar C, Maitra A. Polymeric nanoparticle-encapsulated curcumin ("nanocurcumin"): a novel strategy for human cancer therapy. J Nanobiotechnol. 2007;5:3.

18. Anitha A, Maya S, Deepa N, et al. Efficient water soluble O-carboxymethyl chitosan nanocarrier for the delivery of curcumin to cancer cells. Carbohydrate Polymers. 2011;83(2):452-461.

19. Ghosh S, Dungdung SR, Choudhury ST, et al. Mitochondria protection with ginkgolide B-loaded polymeric nanocapsules prevents diethylnitrosamine-induced hepatocarcinoma in rats. Nanomedicine (Lond). 2014;9(3):441-456.

20. Ghosh A, Banerjee T, Bhandary S, et al. Formulation of nanotized curcumin and demonstration of its antimalarial efficacy. Int J Nanomedicine. 2014;9:5373-5387.

21. Lemoine D, Francois C, Kedzierewicz F, et al. Stability study of nanoparticles of poly(epsilon-caprolactone), poly(D, L-lactide) and poly(D, L-lactide-co-glycolide). Biomaterials. 1996;17(22):2191-2197.

22. Parasuraman S, Raveendran R, Kesavan R. Blood sample collection in small laboratory animals. J Pharmacol Pharmacother. 2010; 1(2):87-93.

23. Kim SW, Park KC, Kim HJ, et al. Effects of collagen IV and laminin on the reconstruction of human oral mucosa. J Biomed Mater Res. 2001; 58(1):108-112.

24. Navarro A, Boveris A. Rat brain and liver mitochondria develop oxidative stress and lose enzymatic activities on aging. Am J Physiol Regul Integr Comp Physiol. 2004;287(5):1244-1249.

25. Ghosh D, Ghosh S, Sarkar S, et al. Quercetin in vesicular delivery systems: evaluation in combating arsenic-induced acute liver toxicity associated gene expression in rat model. Chem Biol Interact. 2010;186(1):61-71.

26. Batandier C, Fontaine E, Keriel C, Leverve XM. Determination of mitochondrial reactive oxygen species: methodological aspects. J Cell Mol Med. 2002;6(2):175-187.
27. Mandal AK, Sinha J, Mandal S, Mukhopadhyay S, Das N. Targeting of liposomal flavonoid to liver in combating hepatocellular oxidative damage. Drug Deliv. 2002;9(3):181-185.

28. Mandal AK, Das N. Sugar coated liposomal flavonoid: a unique formulation in combating carbontetrachloride induced hepatic oxidative damage. J Drug Target. 2005;13(5):305-315.

29. Reddy TL, Weber MM. Solubilization, purification, and characterization of succinate dehydrogenase from membranes of Mycobacterium phlei. J Bacteriol. 1986;167(1):1-6.

30. Elingold I, Isollabella MP, Casanova MB, et al. Mitochondrial toxicity and antioxidant activity of a prenylated flavonoid isolated from Dalea elegans. Chem Biol Interact. 2008;171(3):294-305.

31. Davila JC, Davis PJ, Acosta D. Changes in glutathione and cellular energy as potential mechanisms of papaverine-induced hepatotoxicity in vitro. Toxicol Appl Pharmacol. 1991;108(1):28-36.

32. Marklund S, Marklund G. Involvement of the superoxide anion radical in the autoxidation of pyrogallol and a convenient assay for superoxide dismutase. Eur J Biochem. 1974;47(3):469-474.

33. Moragon AC, De Lucas Garcia N, Encarnacion Lopez Fernandez M, Rodriguez-Manzaneque AS, Jimenez Fraile JA. Antioxidant enzymes, occupational stress and burnout in workers of a prehospitalary emergency service. Eur J Emerg Med. 2005;12(3):111-115.

34. Castro VM, Soderstrom M, Carlberg I, Widersten M, Platz A, Mannervik B. Differences among human tumor cell lines in the expression of glutathione transferases and other glutathione-linked enzymes. Carcinogenesis. 1990;11(9):1569-1576.

35. Maiti S, Chatterjee AK. Differential response of cellular antioxidant mechanism of liver and kidney to arsenic exposure and its relation to dietary protein deficiency. Environ Toxicol Pharmacol. 2000;8(4): 227-235.

36. Recknagel RO, Glende EA Jr, Dolak JA, Waller RL. Mechanisms of carbon tetrachloride toxicity. Pharmacol Ther. 1989;43(1):139-154.

37. Manibusan MK, Odin M, Eastmond DA. Postulated carbon tetrachloride mode of action: a review. J Environ Sci Health C Environ Carcinog Ecotoxicol Rev. 2007;25(3):185-209.

38. Goel A, Kunnumakkara AB, Aggarwal BB. Curcumin as "Curecumin": from kitchen to clinic. Biochem Pharmacol. 2008;75(4):787-809.

39. Qureshi S, Shah AH, Ageel AM. Toxicity studies on Alpinia galanga and Curcuma longa. Planta Med. 1992;58(2):124-127.

40. Lao CD, Ruffin MT, Normolle D, et al. Dose escalation of a curcuminoid formulation. BMC Complement Altern Med. 2006;6:10

41. Strimpakos AS, Sharma RA. Curcumin: preventive and therapeutic properties in laboratory studies and clinical trials. Antioxid Redox Signal. 2008;10(3):511-545.

42. Goel A, Jhurani S, Aggarwal BB. Multi-targeted therapy by curcumin: how spicy is it? Mol Nutr Food Res. 2008;52(9):1010-1030.

43. Kalepu S, Nekkanti V. Insoluble drug delivery strategies: review of recent advances and business prospects. Acta Pharm Sin B. 2015;5(5): $442-453$.

44. Weber LW, Boll M, Stampfl A. Hepatotoxicity and mechanism of action of haloalkanes: carbon tetrachloride as a toxicological model. Crit Rev Toxicol. 2003;33(2):105-136.

45. Ramachandran A, Lebofsky M, Baines CP, Lemasters JJ, Jaeschke H. Cyclophilin D deficiency protects against acetaminophen-induced oxidant stress and liver injury. Free Radic Res. 2011;45(2): $156-164$

46. Ramachandran A, Lebofsky M, Weinman SA, Jaeschke H. The impact of partial manganese superoxide dismutase (SOD2)-deficiency on mitochondrial oxidant stress, DNA fragmentation and liver injury during acetaminophen hepatotoxicity. Toxicol Appl Pharmacol. 2011;251(3): 226-233.

47. Debnath S, Ghosh S, Hazra B. Inhibitory effect of Nymphaea pubescens Willd. flower extract on carrageenan-induced inflammation and $\mathrm{CCl}(4)$-induced hepatotoxicity in rats. Food Chem Toxicol. 2013;59: 485-491.

48. Finkel T, Holbrook NJ. Oxidants, oxidative stress and the biology of ageing. Nature. 2000;408(6809):239-247. 
49. Morimoto T, Sunagawa Y, Kawamura T, et al. The dietary compound curcumin inhibits p300 histone acetyltransferase activity and prevents heart failure in rats. J Clin Invest. 2008;118(3):868-878.

50. Ji LL, Stratman FW, Lardy HA. Antioxidant enzyme systems in rat liver and skeletal muscle. Influences of selenium deficiency, chronic training, and acute exercise. Arch Biochem Biophys. 1988;263(1):150-160.

51. Lee CH, Park SW, Kim YS, et al. Protective mechanism of glycyrrhizin on acute liver injury induced by carbon tetrachloride in mice. Biol Pharm Bull. 2007;30(10):1898-1904.

52. Morio LA, Chiu H, Sprowles KA, et al. Distinct roles of tumor necrosis factor-alpha and nitric oxide in acute liver injury induced by carbon tetrachloride in mice. Toxicol Appl Pharmacol. 2001;172(1):44-51.
53. Lee TY, Mai LM, Wang GJ, Chiu JH, Lin YL, Lin HC. Protective mechanism of salvia miltiorrhiza on carbon tetrachloride-induced acute hepatotoxicity in rats. J Pharmacol Sci. 2003;91(3):202-210.

54. Nadler EP, Dickinson EC, Beer-Stolz D, et al. Scavenging nitric oxide reduces hepatocellular injury after endotoxin challenge. Am J Physiol Gastrointest Liver Physiol. 2001;281(1):G173-G181.

55. Inoue $\mathrm{T}$, Kwon $\mathrm{AH}$, Oda M, et al. Hypoxia and heat inhibit inducible nitric oxide synthase gene expression by different mechanisms in rat hepatocytes. Hepatology. 2000;32(5):1037-1044.

56. Luster MI, Simeonova PP, Gallucci RM, Bruccoleri A, Blazka ME, Yucesoy B. Role of inflammation in chemical-induced hepatotoxicity. Toxicol Lett. 2001;120(1-3):317-321.
International Journal of Nanomedicine

\section{Publish your work in this journal}

The International Journal of Nanomedicine is an international, peerreviewed journal focusing on the application of nanotechnology in diagnostics, therapeutics, and drug delivery systems throughout the biomedical field. This journal is indexed on PubMed Central, MedLine, CAS, SciSearch $®$, Current Contents $\AA /$ Clinical Medicine,

\section{Dovepress}

Journal Citation Reports/Science Edition, EMBase, Scopus and the Elsevier Bibliographic databases. The manuscript management system is completely online and includes a very quick and fair peer-review system, which is all easy to use. Visit http://www.dovepress.com/ testimonials.php to read real quotes from published authors.

Submit your manuscript here: http://www.dovepress.com/international-journal-of-nanomedicine-journal 